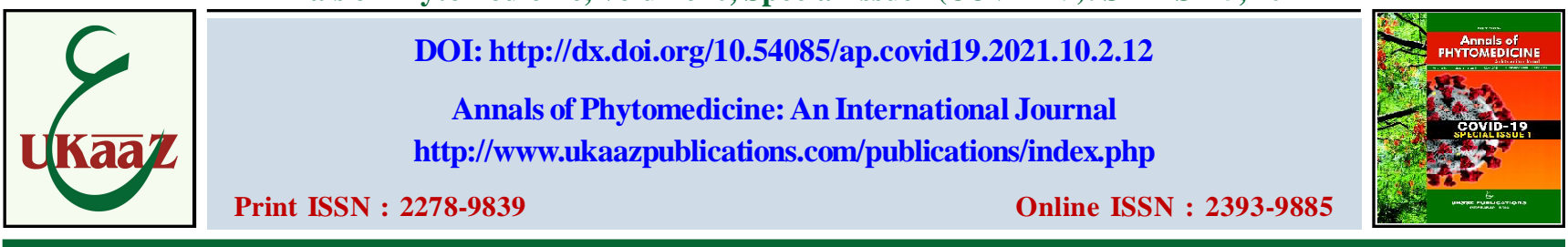

Review Article : Open Access

Special Issue2 (COVID-19)

\title{
Significance and importance of fruits in strengthening immune system during COVID-19
}

Johra Khan**

Department of Medical Laboratory Sciences, College of Applied Medical Sciences, Majmaah University, Al Majmaah, 11952, Saudi Arabia *Health and Basic Sciences Research Center, Majmaah University, Al Majmaah, 11952, Saudi Arabia

\begin{tabular}{l} 
Article Info \\
\hline Article history \\
Received 1 November 2021 \\
Revised 25 December 2021 \\
Accepted 26 December 2021 \\
Published Online 30 December 2021 \\
\hline Keywords \\
Citrus fruits \\
Apple \\
Berries \\
Phytochemicals \\
ACE2 \\
Kiwi
\end{tabular}

\section{Introduction}

The new decade of the $21^{\text {st }}$ century started with the emergence of a novel coronavirus SARS-CoV-2 or COVID-19 in December 2019, which is another community health problem and has been the focus of global attention due to a pneumonia epidemic of unknown cause (Kumar et al., 2021). It has emerged in the huanan seafood market, where livestock animals are also traded, in Wuhan State of Hubei Province in China (Lai et al., 2020). The first case of the COVID-19 epidemic was discovered with unexplained pneumonia on December 12, 2019, and 27 viral pneumonia cases with 7 being severe were officially announced on December 31, 2019 and possible influenza and other CoVs were ruled out by laboratory testing. Chinese authorities announced on January 7, 2020 that a new type of coronavirus (novel coronavirus, $\mathrm{nCoV}$ ) was isolated (Imperial College of London. Report 2: estimating the potential total number of novel coronavirus cases in Wuhan City, China, Jan 2020 (Imai et al., 2020). This virus was named as COVID-19 by WHO on January 2019. New variant cases are still being identified, primarily in other Asian and African countries and in many countries such as the trans-oceanic USA and UK (Pulliam et al., 2021).

During COVID-19, World Health Organization (WHO) announced special dietary suggestion and guidelines for maintaining strong immunity to combat chronic diseases like viral infection including COVID-19. As per WHO, a person should take 5 fruits and vegetables

\section{Corresponding author: Dr. Johra Khan}

Assistant Professor, Department of Medical Laboratory Sciences, College of Applied Medical Sciences,Majmaah University, Al Majmaah, 11952, Saudi Arabia

E-mail: j.khan@mu.edu.sa

Tel.: +966-538077360

Copyright $($ ) 2021 Ukaaz Publications. All rights reserved.

Email: ukaaz@yahoo.com; Website: www.ukaazpublications.com per day but during COVID-19, the serving recommendation was increased to 9 (5 fruits and 4 vegetable) per day (Moreb et al., 2021). Many researches confirmed the entry of SARS-CoV-2 in human is aided by angiotensin-converting enzyme (ACE2) which is a transmembrane enzyme and its level was associated with dietary patterns of the population are found related to ACE levels in their body and in some researches rate of mortality is also connected to the deity intake (Chew et al., 2011; Jaiswal, 2020).

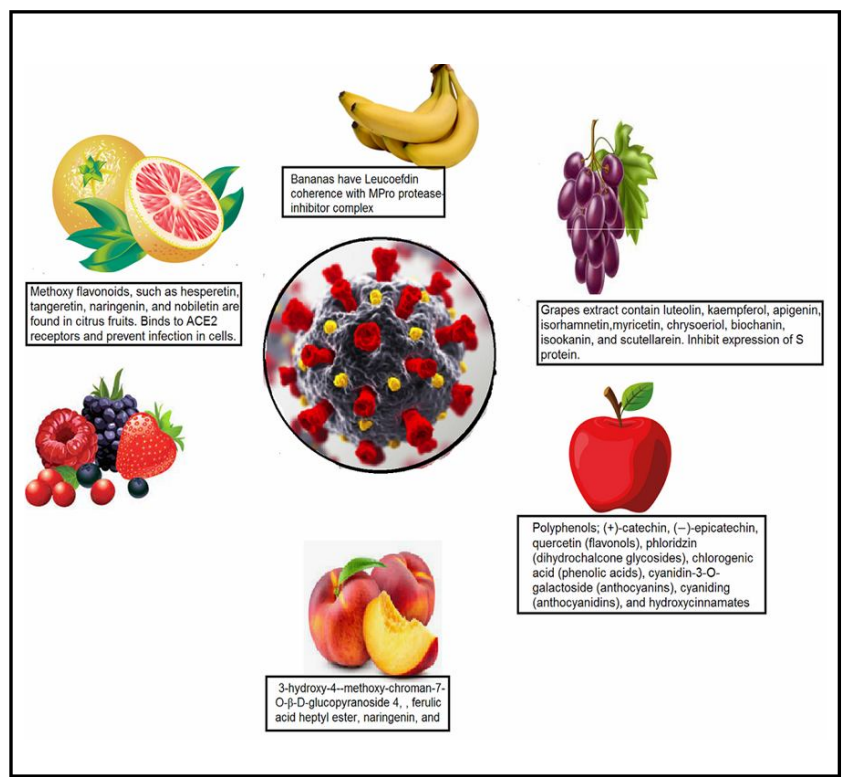

Figure 1: Different fruits and the phytochemical components against SARS-CoV-2. 
From the studies till now, it is identified that protein deficiency can cause the low antibody production and more chances of getting infection (Martindale et al., 2020). The level of nutrition in a body is fundamental necessity for controlling inflammation and oxidative stress, which are directly and indirectly connected to immune system (Cena and Chieppa, 2020). Many nutrients like omega-3 fatty acids, vitamins, and minerals with many phytochemicals (polyphenols, carotenoids) contain anti-inflammatory properties (Garofolo et al., 2021; Rothenberg, 2021). The dietary fibre found in fruits and vegetables helps in gut microbiota stimulation and produce probiotic effect by supporting the growth of bacteria like Bifidobacterium sp., also help in reducing pathogenic bacteria such as Clostridium sp. (O'Shea et al., 2012; Egbuna et al., 2021). These are important to be considered especially in case of SARS-CoV-2 infection due to gastrointestinal problems during COVID-19 and even after recovery (Khan et al., 2021; Rudrapal et al., 2021). In this article, we are providing the information regarding intake of fruits in COVID-19 and their role as immunity booster to combat and recover from this pandemic (Komarayanti et al., 2020; Khanna et al., 2021; Yedjou et al., 2021).

\section{Fruits with healing properties}

\subsection{Citrus fruits}

Fruits are good source of vitamins, alkaloids, and flavonoids with many other phytochemicals which are beneficial for human health. They are also useful for treating many diseases (Rudrapal et al., 2021; Shaikh et al., 2021). The six common flavonoids found in citrus fruits including Citrus reticuata (mandarin), Citrus maxima (pummelo), and Citrus sinensis (sweet orange) are naringin, naringenin, hesperetin, hesperidin, neohesperidin, and nobiletin (Asjad et al., 2013; Cheng et al., 2020). In COVID-19 chronic patient, cytokine storm is observed increase in concentrations of interleukins (IL-1 $\beta$, IL-10), TNF- $\alpha$, and IFN $\gamma$ in plasma (Peterson and Dwyer, 1998; Tripoli et al., 2007). Corticosteroids are recommended to reduce inflammation in lungs, indicating use of anti-inflammatory substances, can help in reducing the severity of COVID-19 clinical symptoms. Anti-inflammatory activity of Citrus naringin was tested in lipopolysaccharide (LPS) treated rats as LPS was found to induce COX-2, IL-1 $\beta$, and IL-6 (Meneguzzo et al., 2020). Naringin in $10,20,40 \mu \mathrm{g} / \mathrm{ml}$ concentration significantly reduce the effect of COX-2, iNOS, IL-1 $\beta$, and IL- 6 and help in lowering the cytokine storm (Tutunchi et al., 2020). As per WHO and different studies on WH-Human_1 sequence of SARS-CoV S-protein shares identical structure of 3-D structure in RBD domain and significant binding affinity toward human ACE2 which is expressed in lungs, kidney, brain, and digestive tract and critical for SARS-CoV-2 entry in host cell (Liu et al., 2016). Zheng and Liu (2020) did docking study to find the interaction of flavonoids with ACE2 (Zheng and Liu et al., 2020). The results showed high binding activity between naringin and ACE2 with docking energy of $-6.85 \mathrm{kcal} / \mathrm{mol}$ and potential binding site at TYR-515, GLU-402, GLU-398, and ASN394, similarly, naringenin shows bind with ACE2 with docking energy of -6.05 $\mathrm{kcal} / \mathrm{mol}$ and with possible binding site at LEU-143, PRO-146, and LYS-131 (Muchtaridi et al., 2020). Hesperidin and hesperetin also showed potential binding affinity to ACE2 with docking energy of $-4.21 \mathrm{kcal} / \mathrm{mol}$ and $-6.09 \mathrm{kcal} / \mathrm{mol}$ with binding sites at ASN-277, ARG-273, HIS-505 with hesperetin, and TRP-69, LEU-351, ASP350 with hesperidin (Biagioli et al., 2021). This study also focused on comparison between the docking studies between chloroquine, baicalin with hesperetin, narigenin, and naringin reporting good potentials of these three flavonoids similar to chloroquine to inhibit the ACE2 (Guler et al., 2021).

\subsection{Kiwi as immunity booster}

Kiwi fruit is also known with names like "China Miracle fruit", "Horticulture wonder of New Zealand", and so on. Kiwi contains good amount of vitamin $\mathrm{C}$, carotenoids, polyphenols, and dietary fibres (Arshad et al., 2020). Researches on kiwi found it to a potential immunity booster. In vitro and in vivo studies on animal models shows significant influence of different biomarkers related to oxidative stress and immune system and also recorded to reduce the frequency and severity of upper respiratory tract infection in comparison to vitamin C supplements alone (Aslam et al., 2017). Kiwi fruit contains the ability of DNA protection from free radicals (Kim et al., 2020; Öztürk and Yücedag, 2021). The flavonoids and phytonutrients present in kiwi was found to reduce shortness of breath by $32 \%$, night cough by $27 \%$, running nose by $28 \%$, and chronic cough by $25 \%$ (Reddy, 2020). Doctors observed that COVID-19 patients who eat three kiwis a day, had low risk of age related muscular degeneration (ARMD) (Arumugam et al., 2021).

\subsection{Apples}

Apples are always considered best for as per the famous saying, "an apple a day, keeps a doctor away". Apples contain high amount of vitamin B, C, and antioxidants, which not only helps in promoting immunity, but also improves digestive system (Kamal et al., 2019). Riboflavin (vitamin B2), a photosensitizer that was used together with UV light to reduce the viral load of batches of blood transfusion and in controlling the titer of MERS-CoV (Middle East respiratory syndrome) related coronavirus which cannot be detected (Cardoso et al., 2012). In vivo study in mice reported that riboflavin decreases inflammation in lungs with significant reduction in neutrophil infiltration (Lu et al., 2004). Some studies also suggest that vitamin B6 supplementation increases total lymphocyte, T-helper and Tsuppressor cells. It is also found to significantly reduce inflammation (Nieva et al., 2006). Apples are also reported to show antiinflammatory activity in human lung cells and tracheal epithelial cells by increasing the pro-inflammatory cytokines and chemokine signalling effect (Chaudhuri et al., 2015). Apple and its juice were found to decrease cell proliferation and allergic reactions of $\mathrm{IgE}$ and mast cell. Apple peels also found to activate macrophages to facilitate tissue repair and direct inhibition of pro-inflammatory pathway by increasing expression of Arg1 gene in lungs (Chaudhuri et al., 2015). Combinations of boysenberry with apple reduce lung inflammation by increasing granulocyte apoptosis mediated interleukin 17A and F (Pajares et al., 2011).

\subsection{Some other fruits}

Other than citrus fruits and apple, some other fruits are also recorded to have nitrate contents present in their flesh, seeds, and skin. Fruits like grapes and berries contain nitrate, resveratrol, anthocyanin, and quercetin which shows protective activity in lung damages and injuries inhibiting TNF- $\alpha$, IL- 8 , modulation Th1 and 2 cells, holding neutrophil and eosinophil recruitment. All of these are responsible of causing cytokine storm in lungs of a COVID-19 patient (Criado and García, 2004). The extract of grape seeds also 
reported to relive viral complications by stopping viral replication, it reduce pro-inflammatory IL-6, IL-88, IL-1 $\beta$, reduce the expression of mucins (Swathi Krishna et al., 2021). The strawberry and blackberry are also big source of dietary nitrates. Study on rat's shows that strawberry extract reduce level of $\operatorname{IgG}$ and IgM in hepatic cells. The extracts of blueberry and strawberry helps in cell survival, and DNA repair (Zhang and Liu, 2020). They are also found to work as immune modulator (Wang et al., 2014).

These fruits also contain flavonoids which help in regulating immune response by regulating receptors and BRD4 (bromodomain containing protein 4) (Nagarajan et al., 2014). Some researchers reported them also to activate nuclear factor erythroid derived 2 related factor 2 (Nrf2), which help in regulating cytokine storm during SARS-CoV-2 infection (Liskova et al., 2021). Pedunculagin, tercatain, and castalin are some hydrolysable tannin showing strong connection sites like Cys 145 and His 41 on 3 CL pro protein of SARS-CoV-2 (Mendonca and Soliman, 2020). Studies by Mazza and Miniati (2018) reported the presence of anthocyanin in strawberry and high amount of it in bush blueberries (Chrz et al., 1993; Mazza and Miniati, 2018). The molecular docking studies of anthocyanin's ligands from berries shows three compounds, pelargonidin-3-glucose, pelargonidin 3 rhamnoside, and procyanidin B2 were targeted on amino acid responsible for interaction between S protein and ACE2 (Karppinen et al., 2018). This will cause disturbance in attachment of SARS-CoV-2 virus with ACE2 in host cell receptor preventing viral infection (Karppinen et al., 2018).

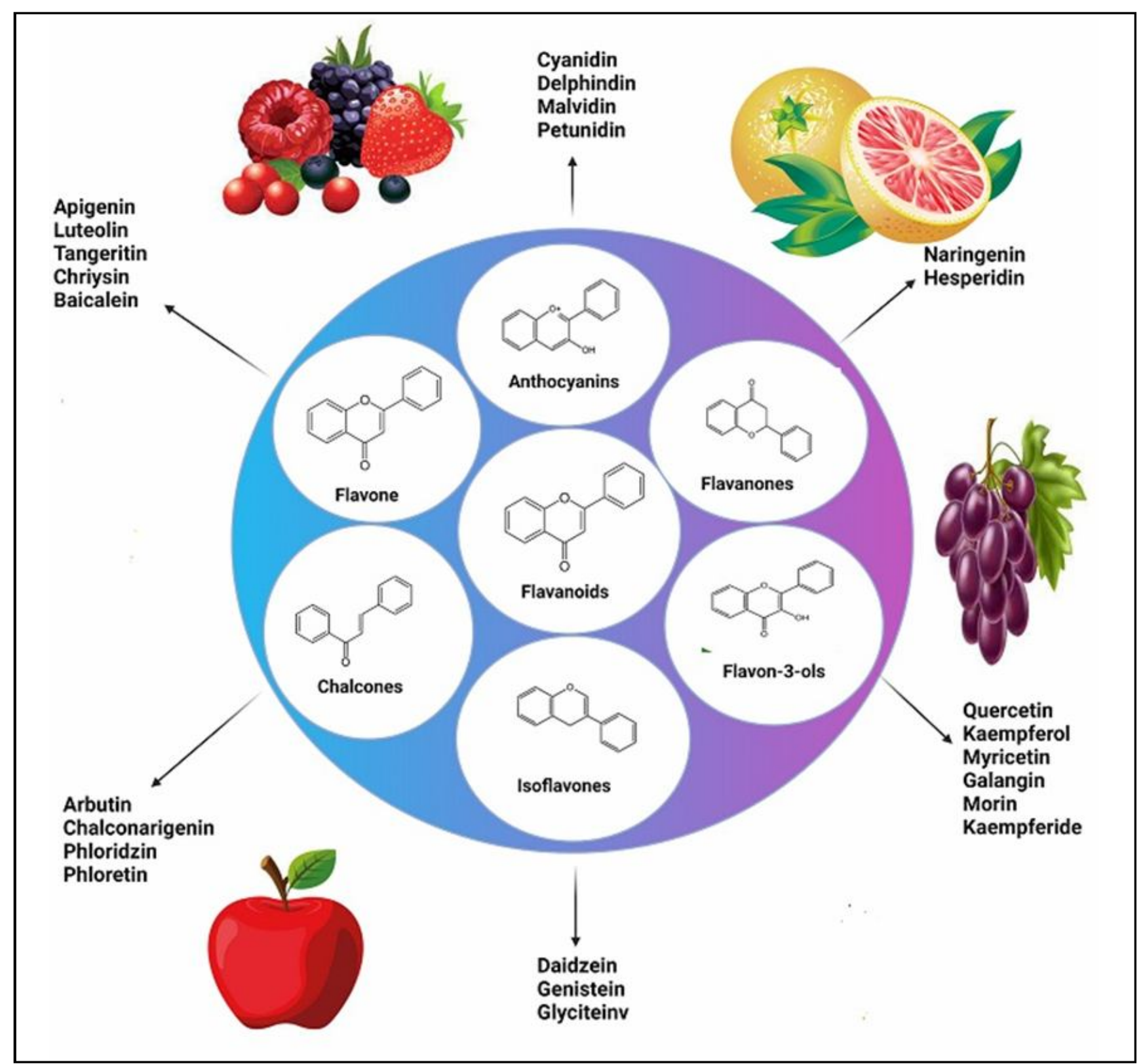

Figure 2: Different phytochemicals found in fruits to fight against COVID-19. 


\section{Conclusion}

Fresh fruits are very important for heath especially during this COVID-19, when need of strong immunity is very high. Fruits which contain significant amount of nitrate can hold the progression of viral disease immediately by either activating or inhibiting different pathways related to SARS-CoV-2 progression. Fruits are home based cheap and readily available remedies that can be implemented to limit the spread of COVID-19 pandemic.

\section{Conflict of interest}

The author declares no conflicts of interest relevant to this article.

\section{References}

Arshad, M.S.; Khan, U.; Sadiq, A.; Khalid, W.; Hussain, M.; Yasmeen, A.; Asghar, Z. and Rehana, H. (2020). Coronavirus disease (COVID 19) and immunity booster green foods: A mini review. Food Sci. and Nu., 8(8):3971-3976.

Arumugam, T.; Sona, C. L. and Maheswari, M. U.(2021). Fruits and vegetables as superfoods: Scope and demand. J. Pharm. Innov., 10:119-129.

Asjad, H.M. M.; Akhtar, M. S.; Bashir, S.; Din, B.; Gulzar, F., Khalid and Asad, M. (2013). Phenol, flavonoid contents and antioxidant activity of six common citrus plants in Pakistan. J. Pharma. and Cos. Sci., 1(1): $1-5$.

Aslam, M. F.; Majeed, S.; Aslam, S. and Irfan, J. A. (2017). Vitamins: Key role players in boosting up immune response. A mini review. Vit. Miner, 6(1):2376-1318.

Biagioli, M.; Marchianò,S.; Roselli, R.; Giorgio, C.; Bellini, R.; Bordoni, M; Gidari, A; Sabbatini, S.; Francisci, D. and Fiorillo, B. (2021). Discovery of a AHR pelargonidin agonist that counter-regulates ACE2 expression and attenuates ACE2-SARS-CoV-2 interaction. Biochem. Pharm., 188:114564.

Cardoso, D. R.; Libardi, S. H. and Skibsted, L. H. (2012).Riboflavin as a photosensitizer. Effects on human health and food quality. Food and Fun., 3(5):487-502.

Cena, H. and M. Chieppa (2020). Coronavirus disease (COVID-19-SARS CoV-2) and nutrition: Is infection in Italy suggesting a connection. Fron. In., immun. 11:944.

Chaudhuri, S.; Sardar, S.; Bagchi, D.; Singha, S. S.; Lemmens, P. and Pal, S. K. (2015). Sensitization of an endogenous photosensitizer: Electronic spectroscopy of riboflavin in the proximity of semiconductor, insulator, and metal nanoparticles. J. of Phy. Chem., 119(18): 4162-4169.

Cheng, L.; Zheng, W.; Li, M.; Huang, J.; Bao, S.; Xu, Q. and Ma, Z. (2020).Citrus fruits are rich in flavonoids for immunoregulation and potential targeting ACE2, Preprints, pp:20-313.

Chew, L.; Prasad, K. N.; Amin, I.; Azrina, A. and Lau, C.(2011). Nutritional composition and antioxidant properties of Canarium odontophyllum Miq. (dabai) fruits. J. of Food Comp.and Ana., 24(4-5):670-677.

Chrz, D.; Maness, N. and Wahem, I. (1993). Yield and quality evaluation of seven strawberry cultivars in eastern oklahoma. Hort. Sci., 28(4): $276 \mathrm{~F}-276$.

Criado, S. and García, N.A. (2004). Vitamin B2-sensitised photooxidation of the ophthalmic drugs Timolol and Pindolol: Kinetics and mechanism. Red. Report, 9(5):291-297.

Egbuna, C.; Awuchi, C. G.; Kushwaha, G; Rudrapal, M.; Patrick-Iwuanyanwu, K. C.; Singh, O.; Odoh, U. E.; Khan, J.; Jeevanandam, J. and Kumarasamy, S. (2021). Bioactive compounds effective against type 2 diabetes mellitus: a systematic review. Cur. Topics in Med. Chem., 21(12): 1067-1095.

Garófolo, A.; Qiao, L. and Maia-Lemos, P. d. S. (2021). Approach to nutrition in cancer patients in the context of the Coronavirus disease 2019 (COVID-19) pandemic: Perspectives. Nut. and Cancer, 73(8):1293-1301.

Guler, H. I.; Fulya, A.; Zehra, C.; Yakup, K.; Belduz, A. O.; Canakci, S. and Kolayli, S. (2021). Targeting CoV-2 Spike RBD and ACE-2 Interaction with flavonoids of anatolian propolis by insilico and in vitro studies in terms of possible COVID-19 therapeutics. Turk. J. Biol., 45(4):530-548.

Imai, N.; Dorigatti, I.; Cori, A.; Donnelly, C.; Riley, S. and Ferguson, N. (2020). Report 2: Estimating the potential total number of novel Coronavirus cases in Wuhan City, China.

Jaiswal, A.K. (2020). Nutritional composition and antioxidant properties of fruits and vegetables, academic press.

Kamal, I.; Zaffar, S.; Malik, J. A. and Ahmad, M. (2019). Effect of apple peel extract on the production of igG immunoglobulins in immuno suppressed mice. J. Postgrad. Med. Inst., 33(3):66.219.22.243.

Karppinen, K.; Tegelberg, P.; Häggman, H. and Jaakola, H. (2018). Abscisic acid regulates anthocyanin biosynthesis and gene expression associated with cell wall modification in ripening bilberry (Vaccinium myrtillus L.) fruits. Fron. in Plant Sci., 9:1259.

Khan, J.; Deb, P. K.; Priya, S.; Medina, K. D.; Devi, R.; Walode, S. G. and Rudrapal, M. (2021). Dietary flavonoids: Cardioprotective potential with antioxidant effects and their pharmacokinetic, toxicological and therapeutic concerns. Mol., 30; 26(13):4021, doi:10.3390/ molecules26134021. PMID: 34209338; PMCID: PMC8272101.

Khanna, K.; Kohli, S. K.; Kaur, R. ; Bhardwaj, A.; Bhardwaj, V.; Ohri, P. ; Sharma, A.; Ahmad, A.; Bhardwaj, R. and Ahmad, P. (2021).Herbal immuneboosters: Substantial warriors of pandemic Covid-19 battle. Phytomed., 85:153361.

Kim, Y. M.; Park, Y. S.; Park, Y. K.; Ham, K. S.; Kang, S. G; Barasch, D.; Nemirovski, A. and Gorinstein, S. (2020). Phytochemical analysis of two main varieties of persimmon and kiwifruit and their antioxidative and quenching capacities. Euro. Food Res. and Tech., 246(6):12591268 .

Komarayanti, S.; Suharso, W. and Herrianto, E. (2020). Local fruits and vegetables of Jember district that can increase immunity during the Covid-19 pandemic. Bir. Ex. Journal, 2(4):492-508.

Kumar, D.; Jahan, S.; Khan,A.; Siddiqui, A. J.; Redhu, N. S.; Khan, J.; Banwas, S.; Alshehri, B. and Alaidarous, A. (2021). Neurological manifestation of SARS-CoV-2 induced inflammation and possible therapeutic strategies against COVID-19. Mol. Neur., pp:1-18.

Lai, X.; Wang,M; Qin, C.; Tan, L.; Ran, L.; Chen, D.; Zhang, H.; Shang, K.; Xia, C. and Wang, S. (2020). Coronavirus disease 2019 (COVID-2019) infection among healthcare workers and implications for prevention measures in a tertiary Hospital in Wuhan. China. JAMA Netw. Open. 3(5):e209666.

Liskova, A.; Samec, M.; Koklesova, L.; Samuel, S. M.; Zhai, K.; Al-Ishaq, R. K.; Abotaleb, M.; Nosal, V.; Kajo, K. and Ashrafizadeh, M. (2021). Flavonoids against the SARS-CoV-2 induced inflammatory storm. Biomed. and Pharm., pp:111-430.

Liu, X.; Wang,N.; Fan, S.; Zheng, X.; Yang, Y.; Zhu, Y.; Lu, Y.; Chen, Q.; Zhou, H. and Zheng, J. (2016). The citrus flavonoid naringenin confers protection in a murine endotoxaemia model through AMPK- 
ATF3-dependent negative regulation of the TLR4 signalling pathway. Sci. Rep., 6(1):1-14.

Lu, C.; Bucher, G. and Sander, W. (2004). Photoinduced interactions between oxidized and reduced lipoic acid and riboflavin (vitamin B2). Chem. Phys. Chem., 5(1):47-56.

Martindale, R.; Patel, J. J.; Taylor, B.; Arabi, Y. M.; Warren, M. and McClave, S. A. (2020). Nutrition therapy in critically ill patients with coronavirus disease 2019. J. Parent. and E.N., 44(7):1174-1184.

Mazza, G. and E. Miniati (2018). Anthocyanins in fruits, vegetables, and grains, CRC press.

Mendonca, P. and Soliman, K. F. (2020). Flavonoids activation of the transcription factor $\mathrm{Nrf2}$ as a hypothesis approach for the prevention and modulation of SARS-CoV-2 infection severity. Antioxid., 9(8):659.

Meneguzzo, F.; Ciriminna, R.; Zabini, N. and Pagliaro, M. (2020). Review of evidence available on hesperidin-rich products as potential tools against COVID-19 and hydrodynamic cavitation-based extraction as a method of increasing their production, Proc., 8(5):549.

Moreb, N. A.; Albandary, A.; Jaiswal, S. and Jaiswal, A. K. (2021). Fruits and vegetables in the management of underlying conditions for COVID19 high-risk groups. J. F., 10(2):389

Muchtaridi, M.; Fauzi, M.; Khairul Ikram, N. K.; Mohd Gazzali, A. and Wahab, H.A. (2020). Natural flavonoids as potential angiotensin-converting enzyme 2 inhibitors for anti-SARS-CoV-2.Mol., 25(17):3980.

Nagarajan, S.; Hossan, T.; Alawi, M.; Najafova, Z. .; Indenbirken, D.; Bedi, U.; Taipaleenmäki, H.; Ben-Batalla, I.; Scheller, M. and Loges, S. (2014). Bromodomain protein BRD4 is required for estrogen receptordependent enhancer activation and gene transcription. Cell Rep., 8(2):460-469.

Nieva, J.; Kerwin, L.; Wentworth, A. D.; Lerner, R.A. and Wentworth P. (2006) Immunoglobulins can utilize riboflavin (Vitamin B2) to activate the antibody-catalyzed water oxidation pathway. Imm. Letters, 103(1):33-38.

O'Shea, N.; Arendt, E. K. and Gallagher, E. (2012). Dietary fibre and phytochemical characteristics of fruit and vegetable by-products and their recent applications as novel ingredients in food products. Innov. F. Sci. and Emer. Tech., 16:1-10.

Öztürk, B. and Yücedað, F. (2021). Effects of methyl jasmonate on quality properties and phytochemical compounds of kiwifruit (Actinidia deliciosa cv.Hayward') during cold storage and shelf life.Turk. J. of Agri.and Forest, 45(2):154-164.

Pajares, A.; Bregliani, M.; Natera, J.; Criado, S.; Miskoski, S.; Escalada, J. P. and García, N. A. (2011). Mechanism of the photosensitizing action of a mixture humic acid-riboflavin in the degradation of water- contaminants. J. Photochem.and Photobio. A: Chem., 219(1): 84-89.

Peterson, J. and Dwyer, J. (1998). Flavonoids: Dietary occurrence and biochemical activity. Nut. Res., 18(12):1995-2018.

Pulliam, J. R.; Van Schalkwyk,C.; Govender, N.; Von Gottberg, A.; Cohen, C.; Groome, M. J.; Dushoff,J.; Mlisana, K. and Moultrie, H. (2021). Increased risk of SARS-CoV-2 reinfection associated with emergence of the Omicron variant in South Africa. Med. Rxiv., pp:320.

Reddy, A.C. (2020). Immunity: A strong defense against coronavirus.

Rothenberg, E. (2021). Coronavirus disease 19 from the perspective of ageing with focus on nutritional status and nutrition management. A narrative review. Nut., 13(4):1294.

Rudrapal, M.; Gogoi, N.; Chetia, D.; Khan, J.; Banwas, S.; Alshehri, B.; Alaidarous, M. A.; Laddha, U. D.; Khairnar, S. J. and Walode, S. G. (2021). Repurposing of Phytomedicine-Derived Bioactive Compounds with promising Anti-SARS-CoV-2 potential: Molecular docking, MD simulation and drug-likeness/ADMET studies. S. J. Bio. Sci., doi: 10.1016/j.sjbs.2021.12.018. Epub ahead of print. PMID: 34924801 ; PMCID: PMC8667520.

Rudrapal, M.; Khan, J.; Dukhyil, A. A. B.; Alarousy, R. M. I. I.; Attah, E. I.; Sharma, T.; Khairnar, S. J. and Bendale, A. R. (2021). Chalcone scaffolds, bioprecursors of flavonoids: Chemistry, bioactivities, and pharmacokinetics. Mol., 26(23):71-77.

Shaikh, Z.; Sundarrajan, P.; Bhagtaney, L.; Zehra, S.; Zahra, K. F.; Badra, B.; Yigit, B. M.; Patel, N.; Alim, H. and Khan, J. (2021). Applicability of vitamins in the management of COVID-19: An overview. Ann. Phytomed., S65-S76.

Swathi Krishna, S.; Thennavan, A. and Kanthlal, S. (2021). Dietary foods containing nitric oxide donors can be early curators of SARS CoV 2 infection: A possible role in the immune system. J. of F Biochem., e13884.

Tripoli, E.; La Guardia, M.; Giammanco, S.; Di Majo, D. and Giammanco, M. (2007). Citrus flavonoids: Molecular structure, biological activity and nutritional properties: A review. F. Chem., 104(2):466-479.

Tutunchi, H.; Naeini, F.; Ostadrahimi, A. and Hosseinzadeh Attar, M. J. (2020). Naringenin, a flavanone with antiviral and anti-inflammatory effects: A promising treatment strategy against COVID 19. Phyto. Res., 34(12):3137-3147.

Wang, L.; Gao, S.; Jiang, W.; Luo, C.; Xu, M.; Bohlin,L.; Rosendahl, M. and Huang, W. (2014). Antioxidative dietary compounds modulate gene expression associated with apoptosis, DNA repair, inhibition of cell proliferation and migration. IJMS. 15(9):16226-16245.

Yedjou, C. G.; Alo, R. A.; Liu, J.; Enow, J.; Ngnepiepa, P.; Long, R.; Latinwo, L. and Tchounwou, P. B. (2021). Chemo-preventive effect of vegetables and fruits consumption on the COVID-19 pandemic. J. of Nut. Food Sci., 4(2).

Zhang, L. and Liu, Y. (2020). Potential interventions for novel coronavirus in China: A systematic review. J. of Med. Virolo., 92(5):479-490. 